\title{
Thermal conductance measurements of bolted copper joints for SuperCDMS
}

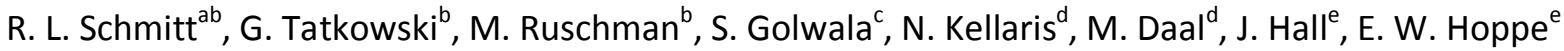

\author{
${ }^{\text {a }}$ Corresponding author: Richard L. Schmitt \\ Address: $\quad$ Fermi National Accelerator Laboratory \\ PO Box 500, Batavia IL, USA 60510-5011 \\ Mail Station 219 \\ Tel: $\quad$ +001 (630) 840-4849 \\ E-mail: $\quad$ rlschmitt@fnal.gov \\ ${ }^{\mathrm{b}}$ Fermi National Accelerator Laboratory, PO Box 500, Batavia IL 60510-5011 \\ ${ }^{\mathrm{C}}$ California Institute of Technology, Pasadena, CA 91125 \\ d University of California Berkeley, Berkeley, CA 94720 \\ ${ }^{\text {e }}$ Pacific Northwest National Laboratory, PO Box 999, Richland WA 99352
}

\begin{abstract}
Joint thermal conductance testing has been undertaken for bolted copper to copper connections from $60 \mathrm{mK}$ to $26 \mathrm{~K}$. This testing was performed to validate an initial design basis for the SuperCDMS experiment, where a dilution refrigerator will be coupled to a cryostat via multiple bolted connections. Copper used during testing was either gold plated or passivated with citric acid to prevent surface oxidation. Results obtained are well fit by a power law regression of joint thermal conductance to temperature and match well with data collected during a literature review.
\end{abstract}

\section{Keywords}

Joint conductance; Contact; Bolt; Copper; Boundary Resistance

\section{Introduction}

As two surfaces become paired, an impedance to the flow of thermal energy between the materials occurs at the joining surface. These impedances can occur for a variety of reasons including the presence of foreign material, a microscopically rough finish, Kapitza resistance, etc. Accurate prediction of thermal conductance across any such joint is critical when designing low temperature equipment, such as the cryostat of the SuperCDMS experiment [1]. In the case of SuperCDMS, detector temperatures below $40 \mathrm{mK}$ are necessary for successful operation. As with previous versions of the experiment, a commercial dilution refrigerator will be used to maintain these required temperatures. However, due to certain constraints such as radiation shielding, maintenance and assembly requirements, etc. the dilution refrigerator will have to be mounted approximately $8 \mathrm{ft}$ from the cryostat via six bolted stem and joint connections. These connections will be made from $\mathrm{C} 101$ copper, which has very favorable bulk thermal conductivity properties. However, surface conditions such as oxidation significantly hinder thermal performance, especially at the joining surfaces, as they are typically regions of lower thermal conductivity; see Nilles [2] and Kittel [3]. Therefore, to ensure reliable performance, copper surfaces will either be gold plated or passivated with citric acid. Both techniques prevent or greatly slow the development of copper oxides in the joint area, thus ensuring optimal thermal conductance through the joint. Citric acid passivation, specifically, creates a more stable surface layer as compared to a copper oxide, and does not increase in thickness over time as a copper oxide layer would. 


\section{Literature review}

A study of over twenty-five publications regarding joint thermal conductance was performed ([2] through [29]). Unfortunately, a large majority of the results were not directly applicable to the SuperCDMS experiment because:

- Joint conductance results relied on electrical resistivity measurements and the use of the Wiedemann-Franz Law, whose use across joints was questioned in Nilles [2] and Didschuns [4].

- Joint clamping force was unknown

- Use of foreign materials such as grease between the joint surfaces. Use of interfacial materials is to be avoided in SuperCDMS to maintain experimental radiopurity and general cleanliness.

Upon review of the pertinent publications; Nilles [2], Kittel [3], Didschuns [4], and Woodcraft [29], a design basis of:

$$
K=6.2 * 10^{-2} W K^{-2} * T-2.3 * 10^{-4} W K^{-1}
$$

for use between temperatures of $60 \mathrm{mK}$ and $26 \mathrm{~K}$ was chosen and deemed to be conservative, as it lies near the lower end of published joint thermal conductance values for various surface preparation and assembly techniques. This design basis estimate was used to size the conduction hardware, such as the stems and joints, and the dilution refrigerator for SuperCDMS. In order to guarantee experimental success of SuperCDMS, testing needed to be performed to compare results of bolted joints which are easy to manufacture and install to the design basis.

\section{Measurements}

Per Didschuns [4], testing was performed using the "two-heater method." A total of nine tests were performed:

A. Seven gold plated single screw joints in series (shown in Figure 1)

1. Between $60 \mathrm{mK}$ and $130 \mathrm{mK}$ using a dilution refrigerator (DR)

2. Between $5.9 \mathrm{~K}$ and $26.4 \mathrm{~K}$ using a pulse tube cryocooler (PT)

3. Between $190 \mathrm{mK}$ and $1 \mathrm{~K}$ using an adiabatic demagnetization refrigerator (ADR)

4. Between $6.8 \mathrm{~K}$ and $8.9 \mathrm{~K}$ using a PT

B. One gold plated single screw joint between $100 \mathrm{mK}$ and $470 \mathrm{mK}$ using an ADR (shown in Figure 2)

C. One gold plated single screw joint between $4.0 \mathrm{~K}$ and $14.0 \mathrm{~K}$ using a PT

D. One gold plated six-screw joint between $3.6 \mathrm{~K}$ and $9.4 \mathrm{~K}$ using a PT (results obtained for this test are presented on a per screw basis in Figure 3 and in Figure 4)

E. One citric acid passivated single screw joint

1. Between $270 \mathrm{mK}$ and $1.1 \mathrm{~K}$ using an ADR

2. Between $6.2 \mathrm{~K}$ and $16.1 \mathrm{~K}$ using a PT 


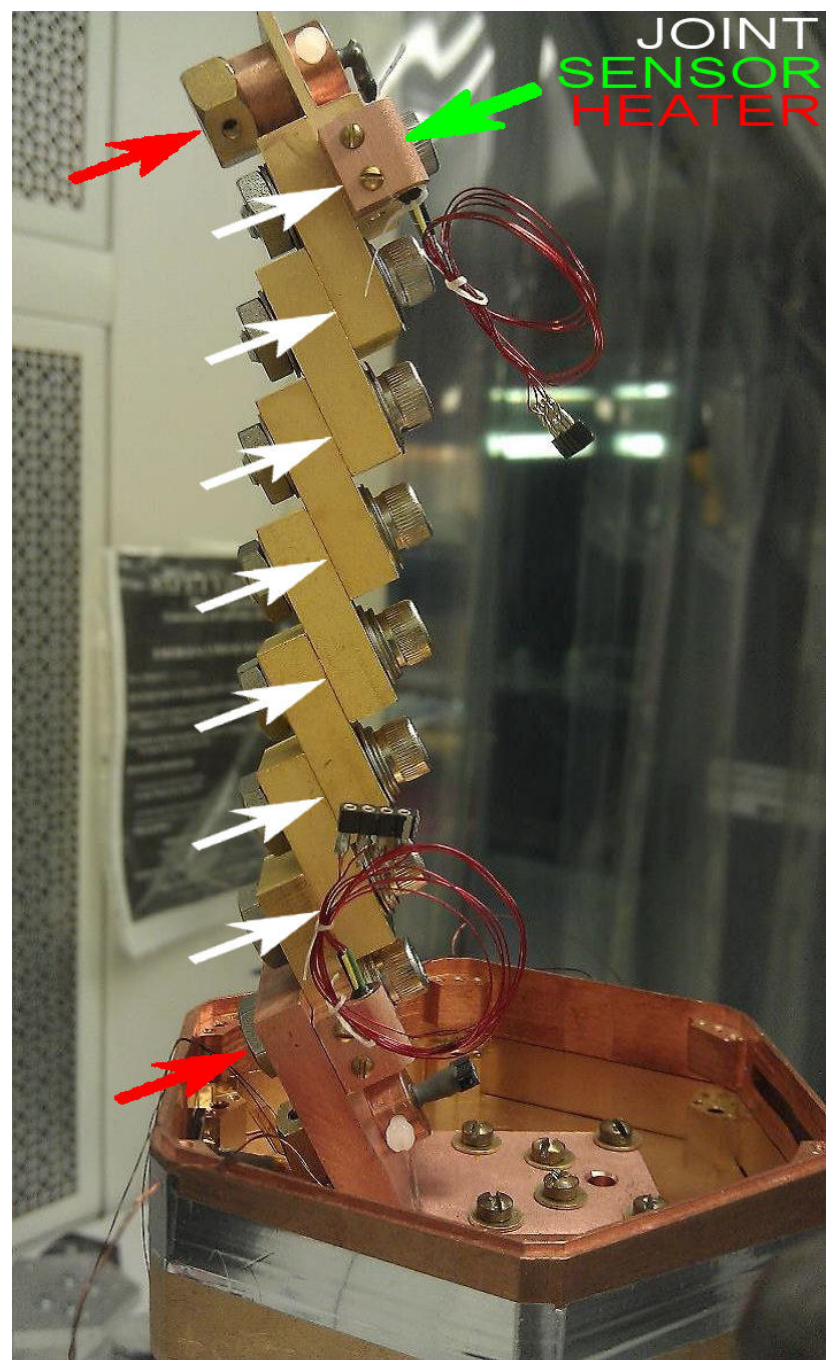

Figure 1: Dilution refrigerator setup from test A.1

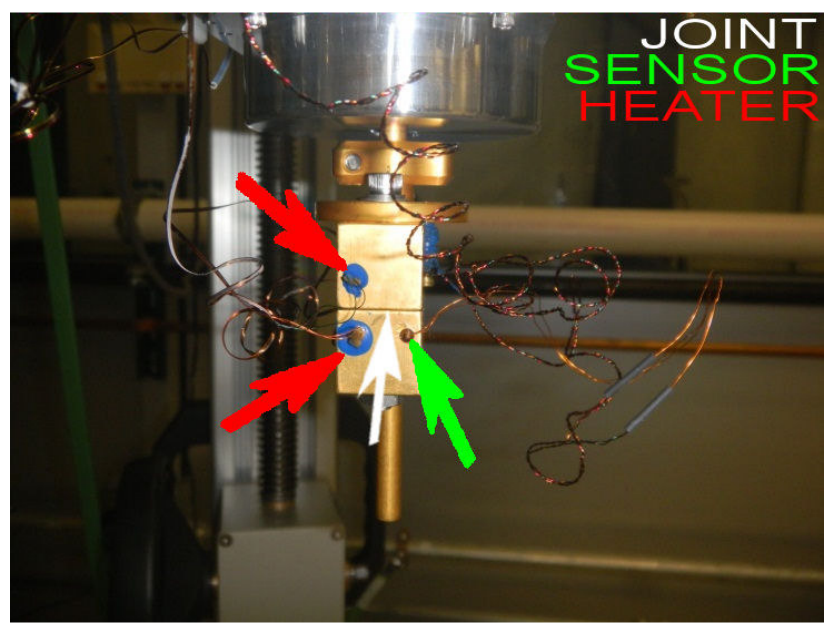

Figure 2: ADR setup from test $B$ 


\section{Test setup}

Information regarding each of the testing groups is presented in Table 1. Non-annealed C101 copper was used for all tests, machined to specifications easily accessible with conventional manufacturing processes ( 0.002 in flatness, $16 \mu$-in surface finish for test group A, $8 \mu$-in surface finish for test groups $B$ through E). Gold plating for test groups A through D was performed at James Precious Metals Plating [31] and was $20 \mu$-in thick over a $50 \mu$-in layer of nickel.

All tests used \#10-32 × 0.75 in 316 stainless steel socket head cap screws with a \#10-32 18-8 stainless steel machine screw hex nut tightened to $25 \mathrm{in}$-lbf. This torque provides an estimated clamping force of $3 \mathrm{kN}$ (which is higher than most values seen in [2] through [29], but identical to Blondelle [13]), and was selected so that brass screws can be used as an option for SuperCDMS assembly. Two nested 0.190 in ID, 0.375 in OD, 0.020 in thick $110 \mathrm{lbf}$ flat load 300 series stainless steel Belleville washers were used with each screw to maintain the bolt preload as the temperature decreased. Finally, \#10 screw size, 7/16 in OD, 316 stainless steel flat washers were used in between the Belleville washers and the copper surfaces to prevent surface scours as bolt load is applied.

To minimize sensor calibration errors and to provide overall experimental simplification, the "two heater" approach recommended in Didschuns [4] was utilized for all testing. As explained, there are economic and practical advantages of having two heaters and one sensor, mainly that heater power can be very accurately applied to the "hot end" (the side furthest from the refrigerator) and "cold end" (the side heat sunk to the refrigerator) of the testing sample using basic laboratory equipment. Using one sensor affixed to the "hot end" also reduces calibration errors as opposed to using multiple sensors.

The "two heater" testing procedure was conducted as follows:

1. Apply "hot end" heater power $(Q)$ to reach a required refrigerator cold plate temperature. Record steady-state "hot end" temperature $\left(T_{1}\right)$.

2. Turn off "hot end" heater. Apply "cold end" heater power equal to heater power used in step $1(Q)$. Record steady-state "hot end" temperature $\left(T_{2}\right)$.

3. Report thermal conductance, $K$, and the average "hot end" temperature $\left(\frac{T_{1}-T_{2}}{2}\right)$.

$$
K=\frac{Q}{T_{1}-T_{2}}
$$

Equal power was generated by both heaters in the "two heater" method by utilizing an HP 6114A (Fermilab) or Keithley 213 (Berkeley) power supply with a HP model 3457A (Fermilab) or 3478A (Berkeley) multimeter reporting amperage and voltage measurements. Multimeters used were calibrated with resistors of known resistance prior to testing. Additionally, all wires were heat sunk to the cold plate of the respective refrigerators to reduce extraneous heat loads.

\section{Citric acid passivation}

Test E was performed with citric acid passivated samples to determine if the passivation could be used as a replacement for gold plating for the stem and joint connections between the dilution refrigerator and the cryostat. Advantages of the citric acid passivation include considerable costs savings and the avoidance of using nickel, which can introduce radioactive contamination and negatively impact the magnetically sensitive SQUIDs used in SuperCDMS. However, as determined during testing, extreme handling measures need to be taken to preserve the passivated finish. It was noted that polishing the blocks with ScotchBrite pads or touching the surfaces with bare hands spoiled the passivated finish. Additionally, variations in processing such as solution chemistry can significantly affect the layer thickness (which was not measured for samples in test group E) and alter the thermal performance of the joint. The passivation procedure can be briefly summarized as follows: 
1. Clean surface with suitable detergent solution and rinse with water.

2. Immerse part in solution of $1 \%$ sulfuric acid by volume, $3 \%$ hydrogen peroxide by volume, and balance water for 3-5 minutes. Rinse part with water.

3. Immerse part in solution of $1 \%$ citric acid by weight and balance water for 1 minute. Rinse part with water.

4. Bake parts for $24 \mathrm{~h}$ at $100^{\circ} \mathrm{C}$.

Citric acid passivation for test E was performed per Hoppe [30] at Pacific Northwest National Laboratory [32].

\begin{tabular}{|c|c|c|c|c|c|}
\hline Test group & A & $B$ & $\mathrm{C}$ & $\mathrm{D}$ & $E$ \\
\hline $\begin{array}{c}\text { Block } \\
\text { dimensions }\end{array}$ & $\begin{array}{c}1.00 \text { in } \times 0.75 \text { in } \\
\times 0.25 \text { in }\end{array}$ & $\begin{array}{c}0.75 \text { in } \times 0.75 \text { in } \\
\times 0.75 \text { in }\end{array}$ & $\begin{array}{c}0.75 \text { in } \times 0.75 \text { in } \\
\times 0.75 \text { in }\end{array}$ & $\begin{array}{c}2.00 \text { in } x 1.38 \text { in } \\
\times 0.75 \text { in }\end{array}$ & $\begin{array}{c}0.75 \text { in } \times 0.75 \text { in } \\
\times 0.75 \text { in }\end{array}$ \\
\hline $\begin{array}{l}\text { \# Screws } \\
\text { per joint }\end{array}$ & 1 & 1 & 1 & 6 & 1 \\
\hline $\begin{array}{l}\text { \# Joints in } \\
\text { series }\end{array}$ & 7 & 1 & 1 & 1 & 1 \\
\hline $\begin{array}{l}\text { Test (“hot } \\
\text { end”) } \\
\text { sensors }\end{array}$ & $\begin{array}{c}\text { Calibrated } \\
\text { Lakeshore Ge } \\
\text { sensor }\end{array}$ & $\begin{array}{l}\text { Calibrated } \\
\text { RuOx sensor }\end{array}$ & $\begin{array}{l}\text { Scientific } \\
\text { Instruments } \\
\text { group A } \\
\text { calibrated Si } \\
\text { diode }\end{array}$ & $\begin{array}{l}\text { Scientific } \\
\text { Instruments } \\
\text { group A } \\
\text { calibrated Si } \\
\text { diode }\end{array}$ & $\begin{array}{l}\text { Scientific } \\
\text { Instruments } \\
\text { group A } \\
\text { calibrated Si } \\
\text { diode }\end{array}$ \\
\hline $\begin{array}{l}\text { Sensor } \\
\text { wiring }\end{array}$ & $\begin{array}{c}\varnothing .003^{\prime \prime} \\
\text { Manganin wire }\end{array}$ & $\begin{array}{c}\text { Lakeshore } \\
\text { Cryotronics } 32 \\
\text { gauge Quad- } \\
\text { Twist wire }\end{array}$ & $\begin{array}{c}\text { Lakeshore } \\
\text { Cryotronics } 32 \\
\text { gauge Quad- } \\
\text { Twist wire }\end{array}$ & $\begin{array}{c}\text { Lakeshore } \\
\text { Cryotronics } 32 \\
\text { gauge Quad- } \\
\text { Twist wire }\end{array}$ & $\begin{array}{c}\text { Lakeshore } \\
\text { Cryotronics } 32 \\
\text { gauge Quad- } \\
\text { Twist wire }\end{array}$ \\
\hline Heating & $\begin{array}{c}2 \times 20 \mathrm{k} \Omega \\
\text { heaters }\end{array}$ & $\begin{array}{c}2 \times 1.48 \mathrm{M} \Omega \\
\text { heaters }\end{array}$ & $\begin{array}{c}2 \times 35.6 \Omega \\
\text { heaters }\end{array}$ & $\begin{array}{c}2 \times 35.6 \Omega \\
\text { heaters }\end{array}$ & $\begin{array}{c}2 \times 35.6 \Omega \\
\text { heaters }\end{array}$ \\
\hline $\begin{array}{l}\text { Heater } \\
\text { wiring }\end{array}$ & $\begin{array}{l}\text { “Cold end": } \\
\varnothing .010 " \\
\text { phosphor } \\
\text { bronze } \\
\text { “Hot end": } \\
\varnothing .003 " \\
\text { Manganin wire }\end{array}$ & $\begin{array}{c}\text { Lakeshore } \\
\text { Cryotronics } 32 \\
\text { gage Quad- } \\
\text { Twist }\end{array}$ & $\begin{array}{l}28 \text { gauge single } \\
\text { strand copper }\end{array}$ & $\begin{array}{l}28 \text { gauge single } \\
\text { strand copper }\end{array}$ & $\begin{array}{c}\text { Test E.1: } \\
\text { Lakeshore } \\
\text { Cryotronics } 32 \\
\text { gage Quad- } \\
\text { Twist } \\
\text { Test E.2: } \\
28 \text { gauge single } \\
\text { strand copper }\end{array}$ \\
\hline
\end{tabular}

Table 1: Test setup information 


\section{Results}

Figure 3 shows a plot of measured joint thermal conductance versus average joint temperature. As discussed in Didschuns [4], joint thermal conductance does not depend on joint area. Therefore, joint area is not reported in this paper. However, the number of bolts per joint strongly influences joint conductance, therefore results obtained from test $D$ were normalized to a per screw basis to agree with results from tests $A, B, C$, and $E$. The design basis obtained during the literature review is plotted for reference in Figure 3, Figure 4, and in Figure 5.

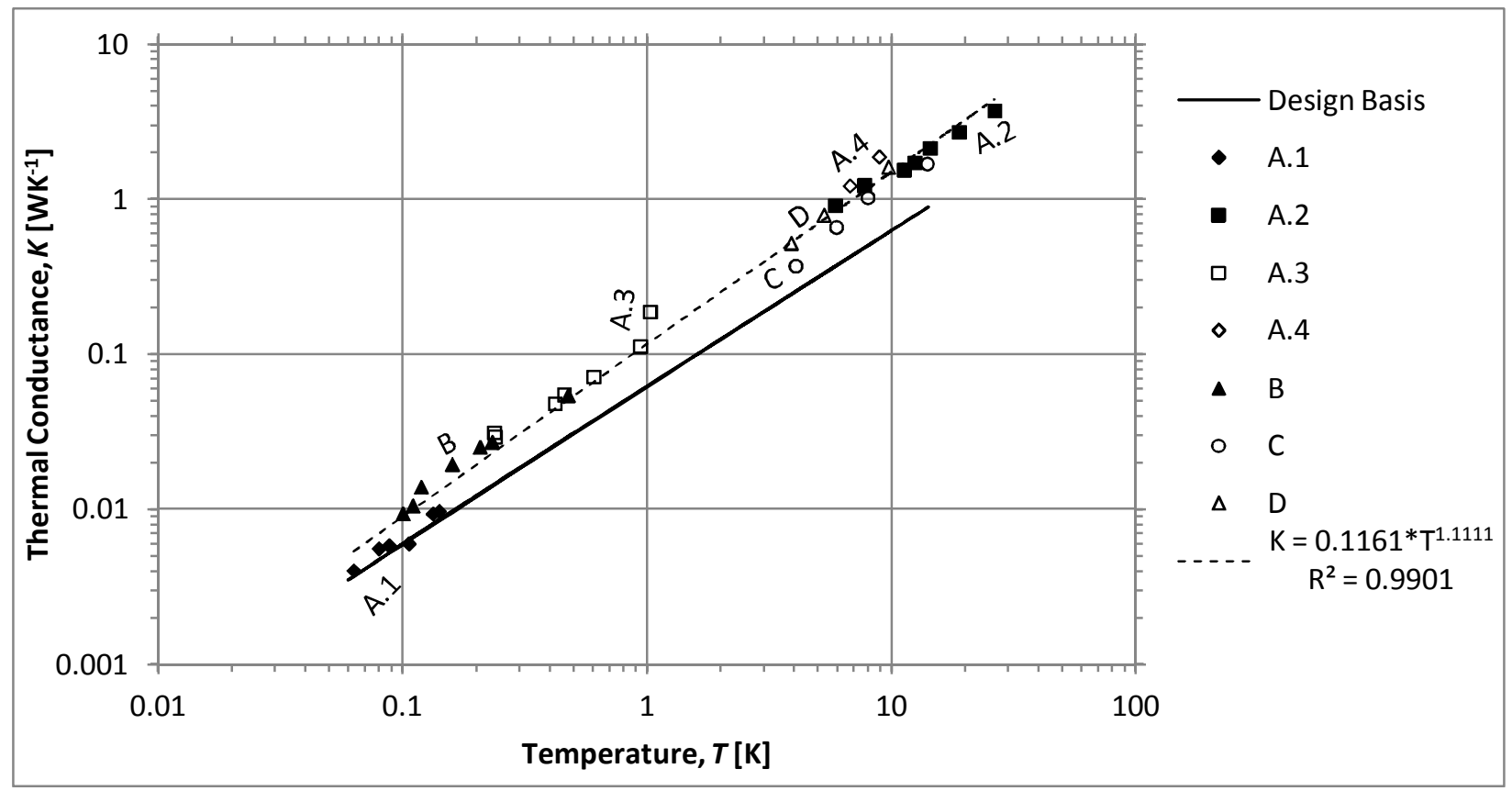

Figure 3: Testing results for testing groups $A$ through $D$ (gold plated joints)

Results from Figure 3 are compared to data obtained from the aforementioned literature review and presented in Figure 4. Data from test group A is plotted separately in Figure 5. 


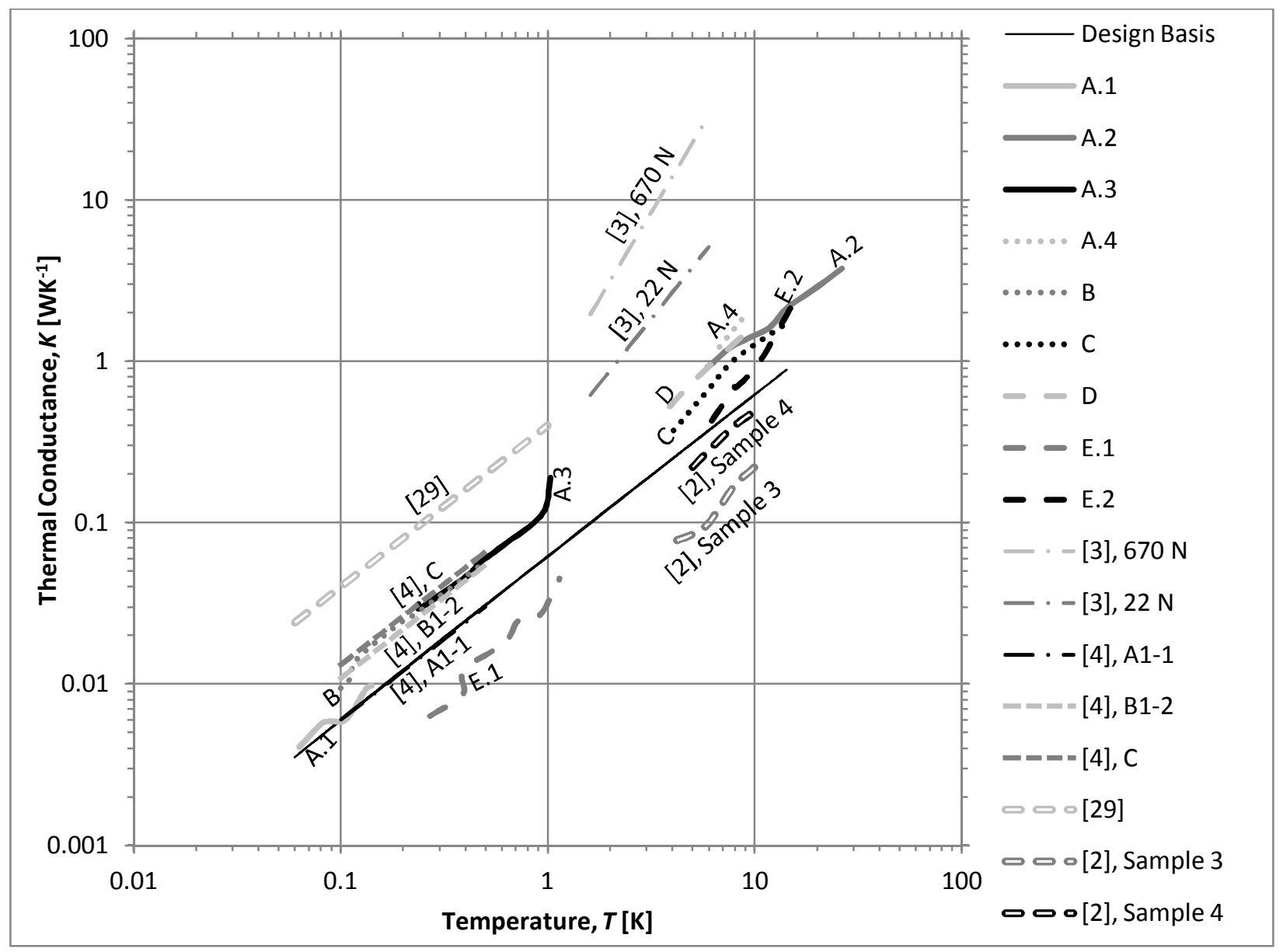

Figure 4: Results from Figure 3 overlaid with data from literature survey

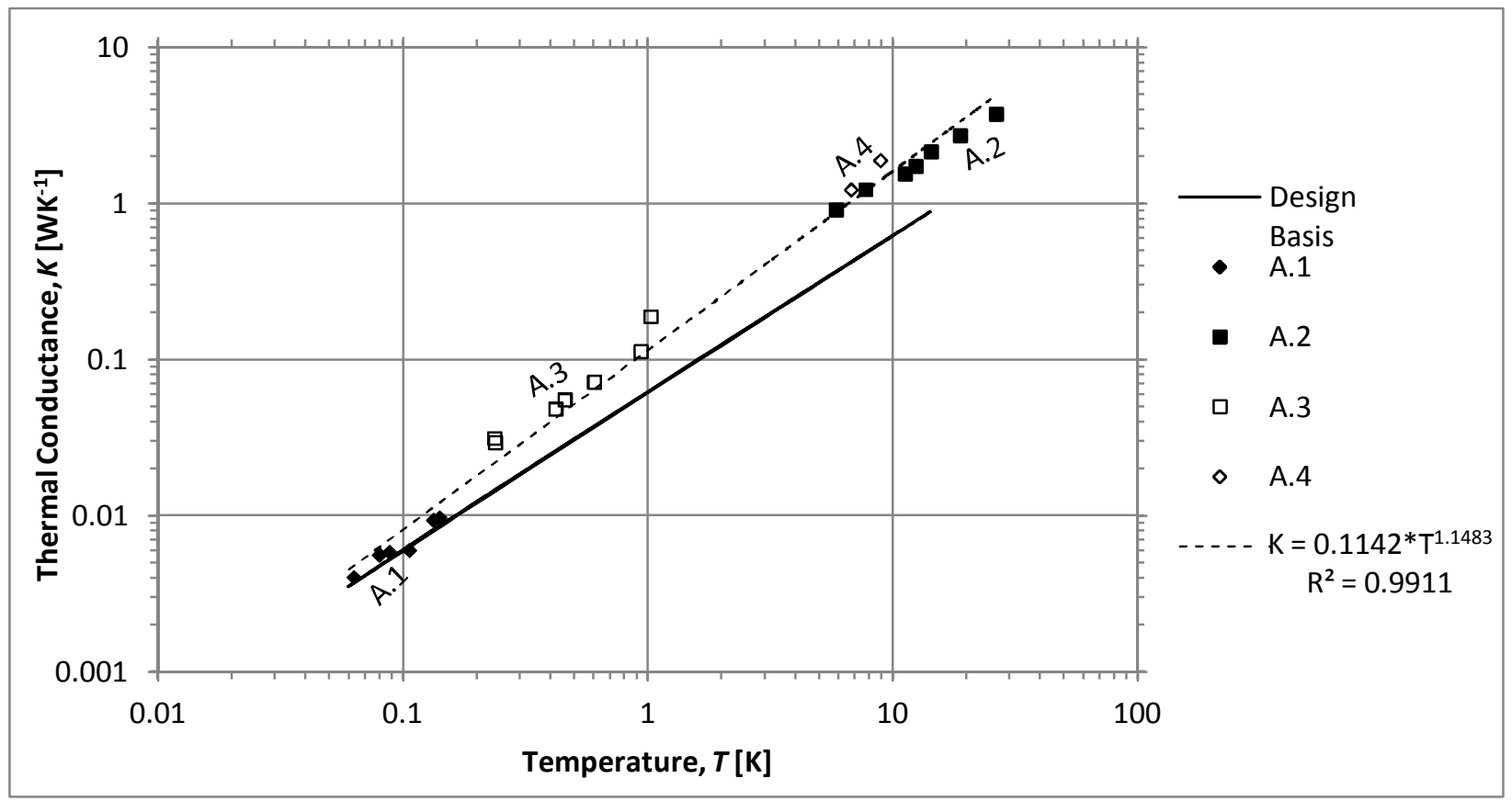

Figure 5: Plot of results obtained for test group A (seven single screw joints in series) 
Lastly, results for joints between citric acid passivated samples are shown in Figure 6.

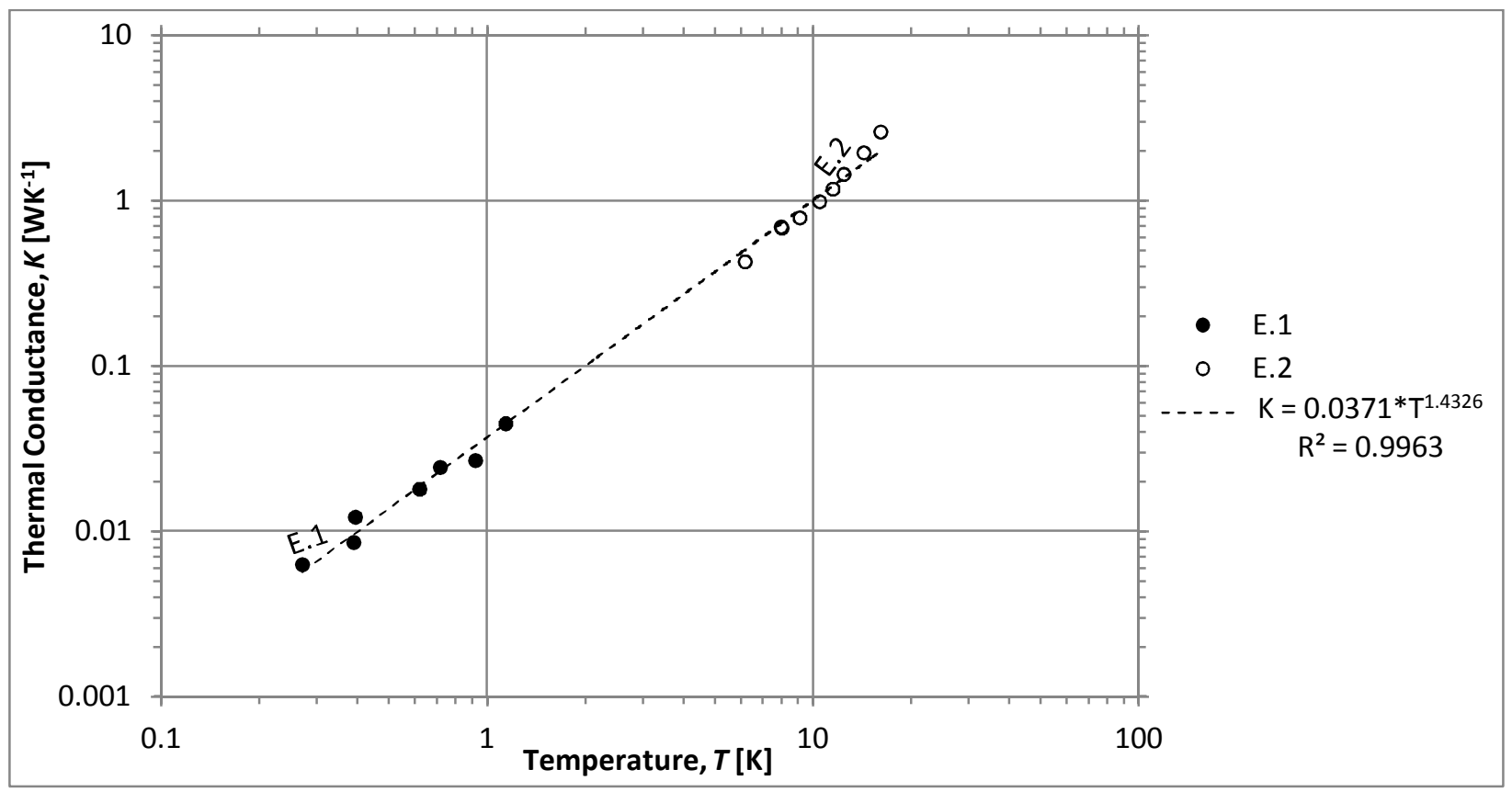

Figure 6: Test group E testing results (citric acid passivated samples)

\section{Analysis and discussion}

As seen in Figure 3, most testing results outperform the SuperCDMS design basis, which gives a strong indication that the initial SuperCDMS stem and joint design is feasible. Results of the regression analyses from Figure 3, Figure 5, and Figure 6 are shown in Table 2. Data obtained follows a power law regression very well, as indicated by high values of coefficient of determination, $R^{2}$, which indicates the fit of the regression to the collected data. A power law behavior was also seen in Kittel [3]; while other references such as Didschuns [4] and Woodcraft [29] suggest a linear behavior.

\begin{tabular}{|r|c|c|c|}
\hline $\begin{array}{l}\text { K: Thermal conductance, } W K^{-1} \\
\text { T:Temperature, } K\end{array}$ & Figure 3 & Figure 5 & Figure 6 \\
\hline Regression equation & $K=0.1161 * T^{1.1111}$ & $K=0.1142 * T^{1.1483}$ & $K=0.0371 * T^{1.4326}$ \\
\hline$R^{2}$ & 0.9901 & 0.9911 & 0.9963 \\
\hline
\end{tabular}

Table 2: Regression analysis results from testing

As seen in Figure 4, results from this testing tend to correlate well with published data, especially data from Didschuns [4]. Additionally, it was verified that joint thermal conductance is dependent on the number of fasteners used, as is seen from normalized test $D$ results in Figure 3 . Proof was also obtained that the conservative design basis is sound, with most testing outperforming the basis. Data from Nilles [2] falls below the design basis; however this is due to the presence of an oxide layer at the joint surface as surfaces were not gold plated in that testing.

Results seen in Figure 4 show that citric acid passivation would yield unacceptable thermal performance for the high heat flux joints in the SuperCDMS experiment between the dilution refrigerator and the cryostat. However, citric acid passivation is a reasonable candidate for the joints between the detector assemblies and the cryostat, where the heat flux per joint is lower and radiopurity requirements are more demanding. 
Results from test A.1 hover at or slightly below the design basis and do not align with results from tests A.2, A.3, or A.4. The source of this discrepancy is not well known; it is speculated to have arisen from the fact that tests were carried out at two different locations: Fermilab and University of California, Berkeley. With this change of location, differing procedures (such as wire heat sinking), personnel, tools (such as torque wrenches) and instrumentation (such as ammeters, voltmeters, wiring, heaters, and temperature sensors) were used, all of which may have introduced a systematic error not seen at Fermilab.

Errors shared amongst tests stem from instrument errors in the voltmeters, ammeters, and the calibrations of the sensors (see Table 1 for sensor information). Heater wiring, especially the copper wiring used in tests C, D, and E.2 will provide an additional heat load to the joint. For tests C, D, and E.2, this heat load is estimated to be less than $1.5 \%$ of the heater power. The percent error between heater powers generated in steps 1 and 2 of the testing procedure is estimated to be less than $0.5 \%$. Radiation heat loads from the refrigerator shielding are estimated to be several orders of magnitude lower than heater loads, and therefore are not predicted to introduce significant error. Lastly, the bolt preload force may have an error as high as $\pm 25 \%$ due to the use of a torque wrench [33].

\section{Conclusions}

As reported in previous papers, such as Didschuns [4], Nilles [2], Kittel [3], or Woodcraft [29], joint thermal conductance through bolted joints at cryogenic temperatures is a function of many variables including bolting force, quantity of fasteners, surface finish, and any plating which may be present. It is not a function of bolting area. Testing performed for SuperCDMS featured bolted copper to copper joints with $3 \mathrm{kN}$ of clamping force. Several bolt configurations were tested, and it was verified that joint thermal conductance is dependent on the quantity of fasteners. Furthermore, two different surface finishes were tested; $20 \mu$-in thick gold plating over a $50 \mu$-in layer of nickel, and citric acid passivation. All other parameters were selected to be easily obtainable by conventional machining practices.

As seen in Figure 3, most testing of gold plated copper joints outperformed the initial design basis, which is welcome news to the SuperCDMS experiment. Citric acid passivated joints were determined to be ineffective for the stem and joint connections between the dilution refrigerator and the cryostat of SuperCDMS, even though significant economic benefits exist when comparing manufacturing cost of citric acid passivated joints to that of gold plated joints. Lastly, it should be emphasized that citric acid passivation is delicate; samples with citric acid passivation require extreme precautions during cleaning and handling.

\section{Acknowledgements}

Fermi National Accelerator Laboratory is operated by Fermi Research Alliance, LLC under Contract No. De-AC02-07CH11359 with the United States Department of Energy. Fermilab report number: FERMILAB-PUB-14-522-PPD.

\section{References}

[1] J. Sander, (SuperCDMS Collaboration), AIP Conf. Proc. 1534, 129 (2012), doi:10.1063/1.4807350.

[2] M. J. Nilles, S. W. Van Sciver. Effects of oxidation and roughness on Cu contact resistance from 4 to $290 \mathrm{~K}$, Advances in Cryogenic Engineering 34 (1987).

[3] P. Kittel, A.L. Spivak, L.J. Salerno. Thermal conductance of gold plated metallic contacts at liquid helium temperatures. Advances in Cryogenic Engineering 37 (1992), 241-248.

[4] I. Didschuns, A. L. Woodcraft, D. Bintley, P.C. Hargrave. Thermal conductance measurements of bolted copper to copper joints at sub-Kelvin temperatures. Cryogenics 44 (2004), 293-299.

[5] M. Manninen, W. Zimmermann, Jr. On the use of screw-fastened joints for thermal contact at low temperatures. Rev. Sci. Instrum. 1977;48:1710. 
[6] R. I. Boughton, N.R. Brubaker, R.J. Sarwinski. Solderless thermal connector for use at low temperatures. Rev. Sci. Instrum. 38, 1177 (1967).

[7] K. Muething, G. G. Ihas, J. Landau. Metallic thermal connectors for use in nuclear refrigeration. Rev. Sci. Instrum., Vol. 48, No. 7, July 1977.

[8] K. M. Lau, W. Zimmermann, Jr. Screw-fastened joints for thermal contact at low temperatures. Rev. Sci. Instrum. 50 (2), Feb. 1979.

[9] T. Okamoto, H. Kukuyama, H. Ishimoto, S. Ogawa. Electrical resistance of screw-fastened thermal joints for ultra-low temperatures. Rev. Sci. Instrum. 61 (4), April 1990.

[10] R. Berman. Some experiments on thermal contact at low temperatures. Journal of Applied Physics. Volume 27, Number 4, April 1956.

[11] R. Berman, C. F. Mate. Thermal contact at low temperatures. Nature, 182 (4650) 1661-1663, 1958.

[12] A. L. Woodcraft. Comment on 'thermal boundary resistance of mechanical contacts between solids at sub-ambient temperatures'. J. Phys. D: Appl. Phys. 34 (2001) 2932-2934.

[13] F. Blondelle, A. Sultan, E. Collin, H. Godfrin. Electrical conductance of bolted copper joints for cryogenic applications. J. Low Temp. Phys. (2014) 175:877-887

[14] R. Radebaugh, J. D. Siegwarth, W. N. Lawless, A. J. Morrow. Electrocaloric refrigeration for superconductors. NBSIR 76-847.

[15] M. Suomi, A. C. Anderson, B. Holmstrom. Heat transfer below 0.2 K. Physica. Volume 38. 1968, 67-80.

[16] A. R. Kerr, N. Horner. Addendum to EDTN No. 163: The low temperature thermal resistance of high purity copper and bolted copper joints. NRAO Electronics Division Technical Note No. 163. August 1992.

[17] A. R. Kerr, N. Horner. The low temperature thermal resistance of high purity copper and bolted copper joints. NRAO Electronics Division Technical Note No. 163. August 1991.

[18] D. Bintley, A. L. Woodcraft, F. C. Gannaway. Millikelvin thermal conductance measurements of compact rigid thermal isolation joints using sapphire-sapphire contacts, and copper and beryllium-copper demountable thermal contacts. Cryogenics 47 (2007) 333-342.

[19] E. G. Wolff, D. A. Schneider. Prediction of thermal contact resistance between polished surfaces. International Journal of Heat and Mass Transfer 41 (1998) 3469-3482.

[20] K. A. Corbett, A. Sawada, E. N. Smith. Thermal and electrical conductance across copper joints below 100 mK. Physica B 194-196 (1994) 1211-1212.

[21] S. W. Van Sciver, M. J. Nilles, J. Pfotenhauer. Thermal and electrical contact conductance between metals at low temperatures. Proceedings of the 1984 Space Cryogenics Workshop, Berlin, Germany, August 7-9, 1984.

[22] M. J. Nilles, Thermal and electrical contact resistance of OFHC Cu from 4K to 290K. Thesis, University of Wisconsin-Madison, December 1986.

[23] M. Deutsch. Thermal conductance in screw-fastened joints at helium temperatures. Cryogenics. May 1979 273-274.

[24] L. J. Salerno, P. Kittel, A. L. Spivak. Thermal conductance of pressed copper contacts at liquid helium temperatures. AIAA Journal, Vol. 22, No. 12 (1984), pp. 1810-1816.

[25] L. J. Salerno, P. Kittel, A. L. Spivak. Thermal conductance of pressed metallic contacts augmented with indium foil or Apiezon grease at liquid helium temperatures. Cryogenics 1994 Volume 34, Number 8, 649-654.

[26] B. B. Mikic. Thermal contact conductance; theoretical considerations. Int. J. Heat Mass Transfer, Vol. 17, pp. 205-214, 1974.

[27] L. J. Salerno, P. Kittel. Thermal contact conductance. NASA Technical Memorandum 110429, February 1997. 
[28] K. H. Yoo, A. C. Anderson. Thermal impedance of pressed contacts at temperatures below $4 \mathrm{~K}$. Cryogenics. October 1983. 531-532.

[29] A.L. Woodcraft, M.I. Hollister, D. Bintley, F.C. Gannaway, D.C. Gostick, W.S. Holland. Thermal design and performance of the SCUBA-2 instrument 1-K and mK systems. Cryogenics 49 (2009), 504-513.

[30] E.W. Hoppe, A. Seifert, C.E. Aalseth, P.P. Bachelor, A.R. Day, D.J. Edwards, T.W. Hossbach, K.E. Litke, J.I. McIntyre, H.S. Miley, S.M. Schulte, J.E. Smart, G.A. Warren. Cleaning and passivation of copper surfaces to remove surface radioactivity and prevent oxide formation. Nuclear Instruments and Methods in Physics Research A 579 (2007), 486-489.

[31] James Precious Metals Plating, Chicago, IL, USA

[32] Pacific Northwest National Laboratory, Richland, WA, USA

[33] E. Oberg, F. D. Jones, H. L. Horton, H. H. Ryffel (2000). Machinery's Handbook. $26^{\text {th }}$ edition. pp. 1480 